\title{
Characterizing Mental Health Status of Couples in High-Risk Pregnancy and its Relevant Characteristics
}

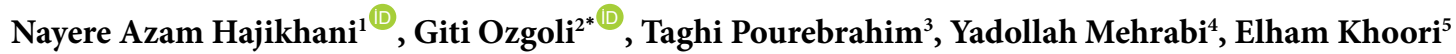

\begin{abstract}
Objectives: Considering the increasing morbidity and mortality in high-risk pregnancies, it is essential to identify the mental health status of women during their pregnancy since this type of pregnancy is associated with the stress for the women and also their spouses. The present study was designed to determine the mental health status of the couples in high-risk pregnancies and its respective characteristics.

Materials and Methods: This cross-sectional study was conducted on couples faced with high-risk pregnancy situations in hospitals and public health centers of Gorgan during 2016-2017. The sample size included 375 couples who were selected by cluster random sampling technique based on the inclusion criteria. Four questionnaires were used to collect the required data. Descriptive and analytical statistics were employed to analyze the obtained data.

Results: The results of the study showed that $31.7 \%$ of mothers and $25.6 \%$ of fathers had mental disorders in high-risk pregnancy situations. Examining the mental health relevant characteristics, the findings indicated an inverse relationship among the following variables: duration of marriage $(P=0.041)$, number of children $(P=0.050)$, maternal age $(P=0.018)$, number of previous pregnancies $(P=0.032)$, age of the spouse $(P=0.013)$, gestational age $(P=0.12)$, social support $(P=0.001)$, and the mean score of pregnant women' mental health. It was found that the above-mentioned factors were associated with an improved mental health. The mean scores for the spouse's mental health $(P=0.000)$, the need for counseling $(P=0.12)$, opening the pregnancy file before the first trimester $(P=0.015)$, and concern $(P=0.000)$ were found to have a direct relationship with the mean score of the pregnant women' mental health.

Conclusions: Checking mental health during prenatal care is recommended to promote the mental health status of the couples encountered with high-risk pregnancy.

Keywords: Mental health, High-risk pregnancy, Relevant characteristics
\end{abstract}

\section{Introduction}

Pregnancy becomes a high-risk situation when either maternal or fetal health and life are compromised by pregnancy-related or other diseases (1). The prevalence of high-risk pregnancy grew during 1994-2013 (2). The incidence of high-risk pregnancies in Iran was reported to be about $63.5 \%$ according to a study by Kashani et al in Gorgan (3). In 2010, 287000 pregnancy-related deaths were reported, $99 \%$ of which occurred in developing countries (4).

High-risk pregnancies are stressful and this stress, during pregnancy, will lead to an increased arterial blood pressure and reduced utero-placent blood flow (5). Not only women but also their husbands are engaged in the psychological effects of high-risk pregnancy (6). Studies in this field have demonstrated that various factors affect the mental health of the couples during pregnancy. A history of mental health disorder, lack of adequate family support, single mothers and physical disorders are among the factors believed to have a negative effect on mental health during pregnancy (7). There is no doubt about the impact of the socio-cultural context as well as the quality and quantity of services provided in each society, on the mental health status of couples during pregnancy (8).

Although the World Health Organization (WHO) and the United Nations Population Fund (UNFPA) have recommended policies for integrating mental health services into primary health care, there are various barriers to prenatal care for pregnant mothers, particularly in lowor middle-income countries. Such barriers include lack of access to prenatal health care services, fear of being labeled when receiving mental health services, lack of expertise in mental health service providers, insufficient delivery of health care services, and poor understanding of mental

Received 31 January 2018, Accepted 9 March 2018, Available online 10 April 2018

${ }^{1}$ Student Research Committee, School of Nursing and Midwifery, Shahid Beheshti University of Medical Sciences, Tehran, Iran. ${ }^{2}$ Midwifery and Reproductive Health Research Center, Department of Midwifery and Reproductive Health, School of Nursing and Midwifery, Shahid Beheshti University of Medical Sciences, Tehran, Iran. ${ }^{3}$ Department of Clinical and Health Psychology, Educational Sciences and Psychology, Faculty Shahid Beheshti University, Tehran, Iran. ${ }^{4}$ Department of Epidemiology, School of Public Health and Safety, Shahid Beheshti, University of Medical Sciences, Tehran, Iran. ${ }^{5}$ Department of Reproductive Health and Midwifery, Counselling and Reproductive Health Centre, Golestan University of Medical Sciences, Gorgan, Iran.

*Corresponding Author: Giti Ozgoli, Tel: +98-912322453, Email: g.ozgoli@gmail.com 
health of mothers by the health care system (9). Today, Iranian health centers have restricted their care for highrisk pregnancies to physical care that targets only women and ignores mental health of the couple during pregnancy.

Accordingly, it seems to be necessary to conduct a study in this field considering the following factors: the high-risk nature of about one third of pregnancies in Gorgan, increased maternal and fetal vulnerability in such pregnancies, the importance of taking mental health into consideration, lack of mental health care for the couples, inadequacy of relevant studies in Iran, studies with contradictory results $(10,11)$, and specific cultural and social characteristics of each society in coping with the stress. Therefore, this study was an attempt to determine the mental health status of the couples in highrisk pregnancies in Gorgan to promote the physical and mental health of the parents.

\section{Materials and Methods}

This cross-sectional study was conducted on pregnant women with high-risk pregnancy and their spouses who had referred to the health centers in Gorgan during 20162017. Stratified cluster random sampling technique was used to select the couples $(\mathrm{N}=375)$ based on the aim of the study. All the women with high-risk pregnancy and their spouses who had no history of mental illness nor psychotherapy and were interested in participating in the study were enrolled.

Data collection instrument consisted of four questionnaires. The first one was a self-administered questionnaire used to collect to sets of data: 1) demographic data, that is, information about participants' income, number of children, insurance status, maternal age, age of the spouse, and duration of marriage and 2) characteristics concerning the couples' mental health.

The second questionnaire was the Symptom Checklist-25 (SCL-25) as a summary of a 90-item SCL including 9 sub-scales to be measured, namely, 'somatization' (6 items); 'obsession' (3 items); 'hypersensitivity in mutual relationships' (3 items); 'depression' (2 items); 'anxiety' (3 items); 'phobia' (3 items); 'paranoid thoughts' ( 1 item); and 'psychosis' (3 items) and 'anorexia' (1 item). Najarian and Dawodi (12) assessed the validity and reliability of this research instrument in Iran and represented that SCL25 had a very high correlation $(r=0.95)$ with the original scale. The cut-off point for each sub-scale and the total score were 2.5 and 1.3 , respectively. In the present study, Cronbach $a$ for all the items showed a total estimation of 0.90 .

The third questionnaire was Pregnancy Worries and Stress Questionnaire (PWSQ) containing six subcategories as follows: 'mother's health' ( 6 items); 'childbirth and mother's experience' (4 items); 'newborn's health' (5 items); 'personal-family bonding' (5 items); 'personal occupational bonding' (3 items); and 'mother-newborn bonding' ( 2 items). Sum of the scores was rated between
0-100. The Cronbach Alpha coefficient was estimated .78 for the whole questionnaire (13). The reliability of Cronbach a was 0.91 in this study.

The fourth questionnaire was the Perceived Social Support Family Scale (PSSFa) that assessed social support provided by the family. The Cronbach a coefficient was between $0.88-0.91$ for the family scale. The total score of the items ranged between 0-20 (14). Besides, the Cronbach a reliability was 0.80 in the current study.

\section{Statistical Analysis}

The data were analyzed using SPSS software, version 19 and also descriptive and analytical statistics. The $t$ test and analysis of variance (ANOVA) were used to compare mental health among different groups of demographic variables. Pearson correlation test was employed for quantitative values as well. In cases where the independent variable was qualitative, $t$ test and multivariate regression analysis were used $(P<0.05)$. Correlation coefficient in quantitative cases and eta coefficient in case of qualitative independent variables were applied to determine the impact factor. In addition, to investigate the relationship between social support, concern, and mental health, correlation coefficients were used.

\section{Results \\ Samples}

The average ages of the mothers and their spouses were $28.76 \pm 7$ and $33.12 \pm 6.8$ years old, respectively. The number of mothers in all trimesters of pregnancy was also equal $(P<0.05)$. Demographic characteristics of the coupled faced with high-risk pregnancy are summarized in Table 1. Current pregnancy status is provided in Table 2.

The results showed that $31.7 \%$ of the mothers and $25.6 \%$ of the fathers in the study suffered from mental disorders. The mean scores of mental health of the mothers and fathers were 1.04 and 0.94, respectively (Tables 3, 4 and 5).

In terms of the total scores of mental health in the first, second, and third trimesters, about $40.7 \%, 30.5 \%$, and $25.7 \%$ of the mothers showed scores above the cut-off point, respectively while this score was above the cut-off point in $27.8 \%, 26.7 \%$, and $22.8 \%$ of the fathers in the first, second and third trimesters, respectively. In addition, the mean score of mothers' mental health in the first, second, and third trimesters of pregnancy was $1.17 \pm 0.71$, $1.02 \pm 0.61,0.96 \pm 0.602$, respectively while the mean score of the fathers' mental health in the first, second, and third trimesters of pregnancy was $0.94 \pm 0.90,1 \pm 0.89$, and $0.86 \pm 0.81$, respectively (Tables 3,4 and 5 ).

According to the findings, most complaints among the women regarding the mental health components during the first trimester were about somatic symptoms, anorexia, and obsessive-compulsive disorder. The correlation was negative so that complaints about somatic symptoms, obsessive-compulsive disorder, anorexia, and generally psychiatric disorders reduced with an increase 
Table 1. Demographic Characteristics of Couples with High-risk Pregnancy

\begin{tabular}{llll}
\hline \multirow{2}{*}{ Variable } & \multicolumn{3}{l}{$\mathbf{n}=\mathbf{3 7 5}$ Mother, $\mathbf{n}=\mathbf{3 7 5}$ Spouse } \\
\cline { 2 - 4 } Income & Group & No. & Percent \\
\hline & Sufficient & 278 & 74.1 \\
& $<$ Sufficient & 17 & 4.5 \\
& 0 & 80 & 21.3 \\
Number of children & 1 & 161 & 42.9 \\
& 2 & 113 & 30.1 \\
& 3 & 73 & 19.5 \\
Insurance status & $>3$ & 16 & 4.3 \\
Variable & Yes & 12 & 3.2 \\
Maternal age $(\mathrm{y})$ & & 92.8 & 348 \\
Age of spouse $(\mathrm{y})$ & 14 & 7.2 & 27 \\
Duration of marriage $(\mathrm{y})$ & 1 & & \\
\hline
\end{tabular}

Table 2. Current Pregnancy Status

\begin{tabular}{|c|c|c|c|}
\hline Variable & Group & No. & Percent \\
\hline \multirow{3}{*}{ Gestational age (wk) } & $<14$ & 108 & 28.8 \\
\hline & $15-28$ & 131 & 34.9 \\
\hline & $29-42$ & 136 & 36.3 \\
\hline \multirow{2}{*}{ Pregnancy planning } & Yes & 251 & 66.9 \\
\hline & No & 124 & 33.1 \\
\hline \multirow{2}{*}{$\begin{array}{l}\text { Refer to filing history during the } \\
\text { first trimester }\end{array}$} & Yes & 294 & 78.4 \\
\hline & No & 81 & 21.6 \\
\hline \multirow{2}{*}{$\begin{array}{l}\text { Visit the centers for counseling } \\
\text { before pregnancy }\end{array}$} & Yes & 106 & 28.3 \\
\hline & No & 269 & 71.7 \\
\hline \multirow{2}{*}{$\begin{array}{l}\text { Visit for prenatal care by the } \\
\text { midwife }\end{array}$} & Yes & 312 & 83.2 \\
\hline & No & 63 & 16.8 \\
\hline \multirow{2}{*}{$\begin{array}{l}\text { Diagnosis of medical condition in } \\
\text { the current pregnancy }\end{array}$} & Yes & 332 & 88.5 \\
\hline & No & 43 & 11.5 \\
\hline \multirow{4}{*}{ Body mass index } & $<18.5$ & 22 & 5.9 \\
\hline & $18.5-24.9$ & 130 & 34.7 \\
\hline & $25-29.9$ & 131 & 34.9 \\
\hline & $>30$ & 92 & 24.5 \\
\hline \multirow{2}{*}{ Take part in the pregnancy class } & Yes & 66 & 17.6 \\
\hline & No & 309 & 82.4 \\
\hline \multirow{7}{*}{ Source of information } & Midwife & 147 & 39.2 \\
\hline & Doctor & 109 & 29.1 \\
\hline & Families & 27 & 7.2 \\
\hline & Book & 22 & 5.9 \\
\hline & Net & 51 & 13.6 \\
\hline & Media & 5 & 1.3 \\
\hline & Social Media & 19 & 5.1 \\
\hline
\end{tabular}

in gestational age (Tables 4 and 5).

Considering mental health-related characteristics, the results suggested that there was an inverse relationship between duration of marriage $(P=0.041)$, number of children $(P=0.050)$, mother's age $(P=0.018)$, number of previous pregnancies $(P=0.032)$, spouse's age $(P=0.013)$, gestational age $(P=0.12)$, social support $(P=0.001)$, and the mean score of pregnant women' mental health. They were associated with an increased mental health. Moreover, the mean scores of spouse's mental health $(P=0.000)$, the need for counseling $(P=0.012)$, opening the pregnancy file before the first trimester $(P=0.015)$, and worry $(P=0.000)$ were found to have a direct relationship with the average mental health score of the pregnant women. That is to say that they were accompanied by disrupted mental health. The highest impact among the quantitative variables was related to general mental health of the spouse (correlation coefficient $=0.236$ ) and the need for a counselor had the highest impact among the qualitative variables as well (eta coefficient $=0.185$ ). The score of social support, among the samples of the study, was 14.45 which was higher than the mean score of 10 . Therefore, the majority of mothers enjoyed social support.

A study of the relationship between mental health score, social support, and worry showed that there was a positive relationship between social support and also mental health and its dimensions indicating that those mothers who received a higher level of support demonstrated a lower score of disorder, that is, they were healthier $(P=0.001$, $\mathrm{R}=-0.168)$. Moreover, there was a positive and significant correlation between worry and mental health indicating that increasing worry would ruin mental health $(P=0.000$, $\mathrm{R}=0.485$ ) (table not listed).

\section{Discussion}

The findings of the present study on frequency and comparison of mental disorders in couples revealed that two-thirds of the samples had a good level of mental health. Mental health disorder in mothers was higher than fathers and the highest frequency of mental health disorder was seen in the first trimester of pregnancy. Furthermore, $31.7 \%$ of mothers with high-risk pregnancy and also $25.6 \%$ of fathers suffered from mental disorders.

The frequency of mental health disorders among mothers with high-risk pregnancies in Iran (15), Italy (16), Sri Lanka (17) and low and middle-income countries (18) was $56.6 \%, 14.9 \%, 22.7 \%$ and $15.6 \%$, respectively. The difference between cultural, social, and economic context of the current study's population and other studies can explain the difference in prevalence of mental disorders between the studied population and the other communities.

In addition, $74.1 \%$ of the samples in the present study had adequate income. Nearly $78.4 \%$ of mothers referred to the respective centers during the first trimester to open a file. The sub-scales like depression, physical complaints, anxiety, and anorexia decreased in mothers with improvement in their economic status, adequacy of income for prenatal care, scheduled referral for prenatal care, and opening a file in the first trimester of pregnancy. It has been found that there was a significant relationship between receiving health care services and mental health status (19).

A comparison of mothers and fathers in terms of mental health indicated that a higher percentage of mothers were 
Table 3. Frequency of Disorder in Mental Health and its Components in Women With High-risk Pregnancy and Their Spouses in Hospitals and Health Centers of Gorgan

\begin{tabular}{lcccccccc}
\hline & \multicolumn{2}{c}{ 1st Trimester } & \multicolumn{2}{c}{ 2nd Trimester } & \multicolumn{2}{c}{ 3rd Trimester } \\
\cline { 2 - 7 } & No. & \% & No. & \% & No. & \% & No. & \% \\
\hline Spouses & 30 & 27.8 & 35 & 26.7 & 31 & 22.8 & 96 \\
Mothers & 44 & 40.7 & 40 & 30.5 & 35 & 25.7 & 119 & 31.7 \\
\hline
\end{tabular}

Table 4. The Study of Mental Health Status and its Components Among Mothers in High-Risk Pregnancy

\begin{tabular}{|c|c|c|c|c|c|}
\hline Disorder & $\begin{array}{c}\text { 1st Trimester } \\
\text { Mean } \pm \text { SD }\end{array}$ & $\begin{array}{c}\text { 2nd Trimester } \\
\text { Mean } \pm \text { SD }\end{array}$ & $\begin{array}{c}\text { 3rd Trimester } \\
\text { Mean } \pm \text { SD }\end{array}$ & $\begin{array}{c}\text { Total } \\
\text { Mean } \pm \text { SD }\end{array}$ & $P$ Value \\
\hline Somatization & $1.50 \pm 0.85$ & $1.27 \pm 0.77$ & $1.13 \pm 0.73$ & $1.28 \pm 0.79$ & 0.001 \\
\hline Obsessive-compulsive disorder & $1.17 \pm 0.98$ & $0.92 \pm 0.77$ & $0.89 \pm 0.81$ & $0.98 \pm 0.86$ & 0.026 \\
\hline Interpersonal sensitivity & $1.14 \pm 0.95$ & $1.05 \pm 0.87$ & $1.05 \pm 0.90$ & $1.07 \pm 0.90$ & 0.708 \\
\hline Depression & $0.97 \pm 0.93$ & $1.07 \pm 0.89$ & $0.95 \pm 0.92$ & $1 \pm 0.91$ & 0.506 \\
\hline Anxiety & $1.31 \pm 1.05$ & $1.25 \pm 0.94$ & $1.17 \pm 0.93$ & $1.24 \pm 0.97$ & 0.525 \\
\hline Phobia & $0.97 \pm 0.96$ & $0.90 \pm 0.80$ & $0.83 \pm 0.85$ & $0.89 \pm 0.87$ & 0.495 \\
\hline Paranoid & $1.05 \pm 1.18$ & $1.08 \pm 1.12$ & $1.04 \pm 1.21$ & $1.05 \pm 1.17$ & 0.960 \\
\hline Psychosis & $0.73 \pm 0.74$ & $0.61 \pm 0.63$ & $0.70 \pm 0.71$ & $0.67 \pm 0.69$ & 0.376 \\
\hline Anorexia & $1.68 \pm 1.43$ & $1.02 \pm 1.05$ & $0.84 \pm 1.02$ & $1.14 \pm 1.21$ & 0.000 \\
\hline Mental health & $1.17 \pm 0.71$ & $1.02 \pm 0.61$ & $0.96 \pm 0.60$ & $1.04 \pm 0.64$ & 0.035 \\
\hline
\end{tabular}

Table 5. The Study of Mental Health Status and its Components Among Spouses in High-risk Pregnancy

\begin{tabular}{|c|c|c|c|c|c|}
\hline Disorder & $\begin{array}{c}\text { 1st Trimester } \\
\text { Mean } \pm \text { SD }\end{array}$ & $\begin{array}{c}\text { 2nd Trimester } \\
\text { Mean } \pm \text { SD }\end{array}$ & $\begin{array}{c}\text { 3rd Trimester } \\
\text { Mean } \pm \text { SD }\end{array}$ & $\begin{array}{c}\text { Total } \\
\text { Mean } \pm \text { SD }\end{array}$ & $P$ Value \\
\hline Somatization & $0.99 \pm 0.98$ & $1.08 \pm 0.99$ & $0.89 \pm 0.90$ & $0.99 \pm 0.5$ & 0.260 \\
\hline Obsessive-compulsive disorder & $0.97 \pm 0.88$ & $0.99 \pm 0.96$ & $0.90 \pm 0.91$ & $0.95 \pm 0.92$ & 0.695 \\
\hline Interpersonal sensitivity & $1.18 \pm 1.07$ & $0.99 \pm 0.97$ & $0.90 \pm 0.89$ & $1.01 \pm 0.98$ & 0.087 \\
\hline Depression & $0.90 \pm 1.04$ & $0.97 \pm 1.05$ & $0.82 \pm 0.95$ & $0.89 \pm 1.02$ & 0.485 \\
\hline Anxiety & $0.94 \pm 1.07$ & $1.11 \pm 1.05$ & $0.98 \pm 1.04$ & $1.01 \pm 1.05$ & 0.418 \\
\hline Phobia & $0.69 \pm 0.88$ & $0.83 \pm 0.99$ & $0.67 \pm 0.90$ & $0.73 \pm 0.93$ & 0.318 \\
\hline Paranoid & $1.03 \pm 1.31$ & $1.08 \pm 1.18$ & $0.96 \pm 1.07$ & $1.02 \pm 1.18$ & 0.736 \\
\hline Psychosis & $0.80 \pm 0.93$ & $0.90 \pm 0.95$ & $0.72 \pm 0.92$ & $0.80 \pm 0.94$ & 0.270 \\
\hline Anorexia & $1.01 \pm 1.31$ & $1.07 \pm 1.15$ & $0.93 \pm 1.23$ & $1 \pm 1.22$ & 0.667 \\
\hline Mental health & $0.94 \pm 0.90$ & $1 \pm 0.89$ & $0.86 \pm 0.081$ & $0.94 \pm 0.86$ & 0.424 \\
\hline
\end{tabular}

The mean difference is significant at the 0.05 level.

above the cut-off point compared to the fathers. In the first trimester, $40.7 \%$ of mothers versus $27.8 \%$ of fathers were above the cut-off point.

According to a study in France, mental stress level in couples with high-and-law-risk pregnancies was examined at the end of the first trimester of pregnancy, 3 days after delivery, and nine months after childbirth. The highest level of stress was observed in the first trimester of pregnancy (20). In the present study, the mean score of stress was higher in mothers than fathers. Women physically felt the changes during their pregnancy and were at a higher risk to face the related problems.

Similarly, regarding the mental health status of couples during the three trimesters of pregnancy, according to the findings of the present study, the highest level of mental health disorder was observed in the first trimester of pregnancy. Parents are doubtful during the early stages of pregnancy and when they are assured, through screening test, that their fetus is healthy, the majority of their stress is reduced during the second and third trimesters (20).

Based on the results of this study, mental health status in fathers was not affected by gestational age. However, a study in Portugal examining the anxiety level of the couples during pregnancy demonstrated that anxiety level in couples followed a similar pattern but was higher in the first and third trimesters. The results of the present study are not consistent with those of Teixeira and colleagues' study (6). This lack of conformity can be attributed to the type of pregnancy and the difference in socio-cultural context.

Investigation of mental health status and its components among couples based on gestational age illustrated a significant difference in the aspect of somatic symptoms. A study in Italy showed that pregnant women with high-risk pregnancy had more physical problems than women with normal pregnancies. It was found that physical complaints 
of pregnancy were a symptom of mental disorders that should be addressed (21).

Furthermore, investigation of mental health status and its components among the fathers indicated that physical complaints were more prominent than other components. A study in India intending to examine the status of first time fathers showed that tympanites $(89.56 \%)$ and change in appetite $(82.69 \%)$ were the main physical symptoms reported by fathers during transition to fatherhood (22).

With respect to mental health-related characteristics, the results indicated that longer duration of marriage, older age of the mothers, number of previous pregnancies, spouse's age and gestational age were associated with reduced mental health disorders in mothers. The results of other studies suggested that the lowest level of mental disorder was found in older and younger age groups. It was found that an older age and a longer duration of marriage could reduce psychological problems in such women through improving the relationship between the pregnant mother and her spouse $(23,24)$.

Another study demonstrated that when the spouse was involved in prenatal care, his support reduced the anxiety in woman during her pregnancy. Good communication and supportive behavior of the men were associated with a better mental health status of the women (24).

Moreover, a larger number of children was found to have a correlation with greater mental health. Having a child directly affected mental health of the parents. A cohort study on the factors associated with postpartum depression showed that the incidence of depression in multiparous women was lower than primiparous ones (25).

In addition, it was found that the mean score of the spouse's mental health and the need for a counselor were directly related to the mean score of the pregnant women' mental health. Impaired mental health promoted the need for counseling in the mother. Furthermore, impaired mental health of the pregnant mother would ruin her spouse's mental health. Marital disruption was also more likely when the husband or wife suffered from anxiety disorders. Besides, marital disruption led to increased mental distress and reduced mental health in the spouse (8).

Observing a direct association between social support and mental health was another finding of the current study, that is, mental health disorders were lower in mothers who enjoyed higher levels of social support. Receiving more social support and also having a high degree of self-efficacy, and confidence in pregnancy were among the factors that improved the process of coping with pregnancy and mental health in mothers (26). An issue that highlighted the importance of social support in the current study was that the social support score of the majority of mothers under study was above average which can be an evidence that about $60 \%$ of mothers enjoyed high level of mental health.

However, an inverse relationship was found between factors of worry and mental health suggesting that greater anxiety would disrupt mothers' health. With respect to the concerns during pregnancy, a study by Blackmore et al stressed the distinction between pregnancyrelated concerns and other basic worries and stated that pregnancy-related concerns were associated with an increased risk of mental health problems in mothers (27).

\section{Limitation of the Study}

In this study SCL was considered as a screening test that only identified vulnerability of the subjects. Therefore, for a more accurate evaluation, precise psychiatric assessment and diagnostic tests are suggested for future studies.

\section{Conclusions}

According to the findings of the study, mental health status was suitable in two-third of the couples. Consequently, it is suggested that mental care to be included in prenatal care to promote mental health status of the couples. Screening pregnant mothers and their spouses for diagnosing mental health disorders and their underlying causes in prenatal care programs is also recommended.

\section{Conflict of Interests}

Authors declare that they have no conflict of interests.

\section{Ethical Issues}

Ethical approval was granted by the Medical Researches Ethics Committee at Shahid Beheshti University of Medical Sciences in June 21, 2016 (ethical No. IR.SBMU. RETECH.REC.1395.212).

\section{Financial Support}

Deputy of Research, Shahid Beheshti University of Medical Sciences, Tehran, Iran supported our study.

\section{Acknowledgments}

The present paper is taken from a $\mathrm{PhD}$ thesis conducted in International Branch of Reproductive Health Research Center of Shahid Beheshti University of Medical Sciences, Tehran, Iran. The authors appreciate the couples with high-risk pregnancies as well as personnel of the health centers and the staff at high-risk pregnancy ward of Sayyad Shirazi hospital in Gorgan.

\section{References}

1. Corton MM, Leveno KJ, Bloom SL, Spong CY, Dashe JS. Williams Obstetrics 24/E. 24th ed. McGraw-Hill Education; 2014.

2. Simmons HA, Goldberg LS. 'High-risk' pregnancy after perinatal loss: understanding the label. Midwifery. 2011;27(4):452-457. doi:10.1016/j.midw.2010.02.013

3. Kashani E, Hassanzad A, Arab Ameri M. The rate of the prevalence of high-risk pregnancies and the results on 
pregnant mothers and the effect on parameters after the birth. Adv Environ Biol. 2012;6(3):1319-1324.

4. Maternal mortality. WHO website. http://www.who.int/ mediacentre/factsheets/fs348/en/. Published 16 February 2018

5. Urech C, Fink NS, Hoesli I, Wilhelm FH, Bitzer J, Alder J. Effects of relaxation on psychobiological wellbeing during pregnancy: a randomized controlled trial. Psychoneuroendocrinology. 2010;35(9):1348-1355. doi:10.1016/j.psyneuen.2010.03.008

6. Teixeira C, Figueiredo B, Conde A, Pacheco A, Costa R. Anxiety and depression during pregnancy in women and men. J Affect Disord. 2009;119(1-3):142-148. doi:10.1016/j. jad.2009.03.005

7. Witt WP, DeLeire T, Hagen EW, et al. The prevalence and determinants of antepartum mental health problems among women in the USA: a nationally representative populationbased study. Arch Womens Ment Health. 2010;13(5):425437. doi:10.1007/s00737-010-0176-0

8. Renzaho AMN, Green J, Mellor D, Swinburn B. Parenting, family functioning and lifestyle in a new culture: the case of African migrants in Melbourne, Victoria, Australia. Child Fam Soc Work. 2011;16(2):228-240. doi:10.1111/j.13652206.2010.00736.x

9. Katon JG, Lewis L, Hercinovic S, McNab A, Fortney J, Rose SM. Improving perinatal mental health care for women veterans: description of a quality improvement program. Matern Child Health J. 2017;21(8):1598-1605. doi:10.1007/ s10995-017-2285-0

10. Sundstrom Poromaa I, Comasco E, Georgakis MK, Skalkidou A. Sex differences in depression during pregnancy and the postpartum period. J Neurosci Res. 2017;95(1-2):719-730. doi:10.1002/jnr.23859

11. Matthey S, Barnett B, Ungerer J, Waters B. Paternal and maternal depressed mood during the transition to parenthood. J Affect Disord. 2000;60(2):75-85.

12. Najarian B, Dawodi I. Construction and validation of the SCL questionnaire. Journal of Psychology. 2002;5(2):136149. [Persian].

13. Navidpour F, Dolatian M, Yaghmaei F, Majd HA, Hashemi SS. Examining factor structure and validating the Persian version of the pregnancy's worries and stress questionnaire for pregnant Iranian women. Glob J Health Sci. 2015;7(6):308-318. doi:10.5539/gjhs.v7n6p308

14. Sadeghi Aval Shahr H, Moosavi Sahebalzamani SS, Jahdi F, Neisani Samani L, Haghani H. Relationship between perceived social support in first pregnancy with birth satisfaction in primigravid women referred to Shahid Akbar Abadi Hospital. Preventive Care in Nursing and Midwifery Journal. 2014;4(1):54-64. (Persian)

15. Raygan Shalmani R, Khodakarami N, Haddanzade Khansari SM, Akbarzadeh Bagheban AR. Determining mind's health in pregnant mothers with high and low risk pregnancy. 2013. Journal of Medical Council of I.R.I. 2013;30(4):329-334.
16. Agostini F, Neri E, Salvatori P, Dellabartola S, Bozicevic L, Monti F. Antenatal depressive symptoms associated with specific life events and sources of social support among Italian women. Matern Child Health J. 2015;19(5):11311141. doi:10.1007/s10995-014-1613-x

17. Herath INS, Balasuriya A, Sivayogan S. Physical and psychological morbidities among selected antenatal females in Kegalle district of Sri Lanka: A cross sectional study. J Obstet Gynaecol. 2017;37(7):849-854. doi:10.1080/014436 15.2017.1306697

18. Fisher J, Cabral de Mello M, Patel V, et al. Prevalence and determinants of common perinatal mental disorders in women in low- and lower-middle-income countries: a systematic review. Bull World Health Organ. 2012;90(2):139g-149g. doi:10.2471/blt.11.091850

19. Soltani F, Eskandari Z, Khodakarami B, Parsa P, Roshanaei G. Factors contributing to fear of childbirth among pregnant women in Hamadan (Iran) in 2016. Electron Physician. 2017;9(7):4725-4731. doi:10.19082/4725

20. Dulude D, Belanger C, Wright J, Sabourin S. Highrisk pregnancies, psychological distress, and dyadic adjustment. J Reprod Infant Psychol. 2002;20(2):101-123. doi:10.1080/02646830220134612

21. Pesavento F, Marconcini E, Drago D. [Quality of life and depression in normal and in high-risk pregnancy. Analysis of a sample of 100 women]. Minerva Ginecol. 2005;57(4):451-460.

22. Ganapathy T. Couvade syndrome among 1 st time expectant fathers. Muller Journal of Medical Sciences and Research. 2014;5(1):43-47. doi:10.4103/0975-9727.128944

23. Sepehrmanesh Z. Mental Health and Its Related Factors in Young Women in Kashan City. The Iranian Journal of Obstetrics, Gynecology and Infertility. 2009;12(1):31-41.

24. Sanaati F, Mohammad-Alizadeh Charandabi S, Farrokh Eslamlo H, Mirghafourvand M, Alizadeh Sharajabad F. The effect of lifestyle-based education to women and their husbands on the anxiety and depression during pregnancy: a randomized controlled trial. J Matern Fetal Neonatal Med. 2017;30(7):870-876. doi:10.1080/14767058.2016.1190821

25. Morikawa M, Okada T, Ando M, et al. Relationship between social support during pregnancy and postpartum depressive state: a prospective cohort study. Sci Rep. 2015;5:10520. doi:10.1038/srep10520

26. Hui Choi WH, Lee GL, Chan CH, Cheung RY, Lee IL, Chan CL. The relationships of social support, uncertainty, self-efficacy, and commitment to prenatal psychosocial adaptation. J Adv Nurs. 2012;68(12):2633-2645. doi:10.1111/j.1365-2648.2012.05962.x

27. Blackmore ER, Gustafsson H, Gilchrist M, Wyman C, T GOC. Pregnancy-related anxiety: Evidence of distinct clinical significance from a prospective longitudinal study. J Affect Disord. 2016;197:251-258. doi:10.1016/j. jad.2016.03.008

(C) 2018 The Author (s); This is an open-access article distributed under the terms of the Creative Commons Attribution License (http://creativecommons.org/licenses/by/4.0), which permits unrestricted use, distribution, and reproduction in any medium, provided the original work is properly cited. 